\title{
Questões sociocientíficas com enfoque CTS na formação de professores de Ciências: perspectiva de complementaridade
} Socio-scientific issues with CTS focus on training of science teachers: complementary perspective

\author{
Rosa Oliveira Marins Azevedo ${ }^{1}$ \\ Evandro Ghedin² \\ Maria Clara Silva-Forsberg ${ }^{2}$ \\ Amarildo Menezes Gonzaga²
}

\section{Resumo}

Trabalho teórico que procura evidenciar as possíveis razões pelas quais o enfoque CTS ainda não se inseriu efetivamente no processo educacional e apontar alternativa à sua inserção. Para tanto, aborda a origem do movimento CTS e discute seu enfoque na educação, no ensino de Ciências e na formação de professores. É um estudo numa perspectiva crítica, a partir de uma pesquisa documental centrada na produção científica publicada em livros, teses, trabalhos apresentados em anais de eventos e revistas da área educacional. As leituras permitiram direcionar as discussões, assumindo-se a análise interpretativa para a organização do texto. O estudo evidencia que a formação de professores, pelos problemas apresentados em seus aspectos teórico-epistemológicos e éticos, é o principal obstáculo à inserção do enfoque CTS no processo educacional. Como alternativa, aponta-se a abordagem de questões sociocientíficas com enfoque CTS, em uma perspectiva de complementaridade, como possibilidade de melhorias nos aspectos evidenciados.

Palavras-chave: formação de professores de Ciências; Ciência, Tecnologia e Sociedade (CTS); questões sociocientíficas.

\section{Abstract}

Theoretical work that seeks to highlight the possible reasons why the STS approach has not effectively be inserted in the educational process and point out alternative to its insertion. It thus explores the origin of the STS movement and discusses its focus on education, science teaching and teacher education. It is a study in a critical perspective, from a documentary research focused on scientific production published in books, theses, papers presented in conference proceedings and journals in the field of education. The readings allowed direct the discussions, assuming the interpretative analysis for the organization of the text. The study shows that teacher education, the problems presented in its theoretical and epistemological aspects and ethical, is the main obstacle to the insertion of the STS approach in the educational process. Alternatively, points to issues of socialscientific approach to STS approach in a complementary perspective, as the possibility of improvements in the aspects highlighted.

Keywords: training of science teachers; science, technology and society (STS); socio-scientific issues.

\footnotetext{
1 Instituto Federal de Educação, Ciência e Tecnologia do Amazonas | marinsrosa@yahoo.com.br

2 Programa de Pós-Graduação em Educação em Ciências e Matemática da Rede Amazônica de Educação em Ciências.
} 


\section{Introdução}

Embora as repercussões no campo educacional do movimento Ciência, Tecnologia e Sociedade (CTS) tenham surgido com mais vigor em países do hemisfério norte, as discussões sobre questões sociais envolvendo ciência e tecnologia já ocorrem há mais de três décadas no Brasil. No entanto, apesar dos esforços e as conquistas no campo das pesquisas ao longo desses anos, a apropriação do enfoque CTS pelas instituições de ensino do país foi muito mais no campo discursivo do que verdadeiramente incorporada ao processo educacional, particularmente na formação de professores de Ciências.

Tal situação induz ao entendimento de que houve significativos avanços nos discursos, mas não nas práticas educacionais. Isso nos leva a questionar, considerando a importância do enfoque CTS na educação, as possíveis razões ou obstáculos para que esse enfoque ainda não tenha ocupado o lugar devido no processo educacional e, consequentemente, a buscar alternativa para a sua inserção.

Essas inquietações se fizeram presentes ao longo das discussões no desenvolvimento da disciplina Educação em Ciência, Tecnologia e Cidadania, oferecida em um curso de Doutorado em Educação em Ciências, suscitando ampliação dos estudos realizados e busca por possíveis respostas. É o que nos propomos a fazer por meio deste trabalho, que se traduz em uma pesquisa bibliográfica, tendo como referências centrais Auler (2002), Auler e Bazzo (2001), Linsingen (2007), Santos (2007, 2011), dentre outros, que colocam entre suas temáticas principais de pesquisa o enfoque CTS, além de pesquisadores internacionais como Aikenhead (1994, 2009), Cerezo (1998) e Vaccarezza (1998).

Trata-se, desse modo, de um trabalho teórico em uma perspectiva crítica, centrado na pesquisa documental, que envolveu a produção científica publicada em livros, teses, trabalhos apresentados em anais de eventos e revistas da área educacional. A partir das leituras, elaboramos resenhas e fichamentos que permitiram direcionar as discussões para a organização do texto, que trata da origem do movimento CTS e do enfoque CTS na educação e no ensino de Ciências, além de discutir esse enfoque na formação de professores de Ciências e na abordagem de questões sociocientíficas.

$\mathrm{Na}$ análise das discussões, procuramos seguir o desenho interpretativo considerado a partir das categorias assumidas na perspectiva crítica, esperando que possa contribuir para (re) pensar o processo formativo de professores, particularmente de Ciências, de modo a alterar currículos instituídos e que não atendem mais às necessidades da sociedade contemporânea. Contudo, temos clareza de que as considerações que desenvolvemos não dão conta da complexidade que envolve a temática, mas representa,ndo apenas, uma tentativa de situar as questões e, possivelmente, sugerir caminhos para aprofundamento de estudos. 


\section{Origens do movimento Ciência, Tecnologia e Sociedade (CTS)}

Ainda que as origens do movimento CTS já tenham sido amplamente discutidas, com diferentes ênfases por Linsingen (2007), Auler (2002), Santos e Mortimer (2002), Amorim $(1995)^{3}$, entre outros, consideramos necessário trazer algumas considerações a respeito, na tentativa de revelar as razões que levaram esse movimento a estar entre as principais temáticas discutidas no campo educacional.

A expressão CTS é utilizada para fazer referência às inter-relações entre ciência, tecnologia e sociedade. Uma questão primeira e que parece consenso nessa inter-relação, tomando por base os autores acima mencionados, é pensar a ciência e a tecnologia sempre como uma questão que ocorre dentro do contexto de uma determinada sociedade. No entanto, nem sempre foi assim.

À ciência e à tecnologia, nas sociedades modernas, era depositada fé conferida somente ao poder de uma divindade, o que acabou levando à supervalorização dessas atividades como mito da salvação da humanidade (SANTOS; MORTIMER, 2002). Todavia, nos anos 60 e 70 do Século XX, a degradação ambiental, aliada a outros fatores, fez com que a credibilidade até então favorecida pelo desenvolvimento da ciência e da tecnologia se tornasse alvo de um olhar mais crítico (AULER; BAZZO, 2001). Dessa forma:

O sonho de que o avanço científico e tecnológico geraria a redenção dos males da humanidade estava chegando ao fim, por conta de uma tomada de consciência dos acontecimentos sociais e ambientais associados a tais atividades (MITCHAM, 1990 apud LINSENGEN, 2007, p. 4).

Nesse contexto, ainda de acordo com Auler e Bazzo (2001), ciência e tecnologia passaram a ser objeto de debate político, emergindo assim o denominado movimento amplamente conhecido como Ciência, Tecnologia e Sociedade (CTS), trazendo considerável influência no contexto educacional em diversos países.

Esse movimento, para Cerezo (1998), envolve uma diversidade de estudos e programas de colaboração multidisciplinar que, ao enfatizar a dimensão social da ciência e da tecnologia, rejeita a imagem da ciência como uma atividade pura; critica a concepção de tecnologia como ciência aplicada e neutra; repele a tecnocracia. Tais estudos e programas, de acordo com o autor, têm seguido três grandes direções:

- no campo da investigação - representam uma alternativa à reflexão tradicional em filosofia e sociologia da ciência, promovendo uma visão contextualizada da atividade científica como processo social;

\footnotetext{
${ }^{3}$ É notória, a partir de uma análise das referências utilizadas para as discussões CTS por esses autores nacionais, a grande influência de autores internacionais nas produções brasileiras, a exemplo do canadense Glenn Aikenhead e daqueles vinculados à Organização dos Estados Ibero-americanos para a Educação, a Ciência e a Cultura (OEI). Essa influência também foi observada em uma análise feita a respeito da questão por Invernizzi e Fraga (2007). Isso evidencia que, embora CTS seja um campo em consolidação na América latina, carece de mais investimentos em pesquisas referentes à temática que tomem como referência a sociedade brasileira (LINSINGEN, 2007). Tal situação se torna especialmente relevante se concordamos com Aikenhead (2009) que cada país deve desenvolver o seu próprio sentido de educação científica, objetivo central do enfoque CTS, segundo o autor. Por outro lado, entendemos que é importante considerar que a revisão da literatura internacional pode contribuir para a compreensão de que adotar propostas com enfoque CTS difere radicalmente de abordagens superficiais nos currículos com aspectos do cotidiano (SANTOS; MORTIMER, 2002).
} 
- no campo das políticas públicas - defendem a regulação pública da ciência e da tecnologia, promovendo a criação de diversos mecanismos democráticos que facilitem a abertura de processos de tomada de decisão em questões concernentes a políticas científico-tecnológicas;

- no campo da educação - promovem, guiados pela nova imagem da ciência e da tecnologia na sociedade, o aparecimento em diversos países, de programas e materiais CTS, tanto no ensino secundário quanto no universitário.

Este último campo, que constitui nosso foco de estudo, ainda de acordo com Cerezo (1998), desde o final dos anos 60, reclamou nova forma de entender ciência e tecnologia e suas relações com a sociedade. Isto fez com que nos anos 70 aparecessem numerosas propostas para um planejamento mais crítico e contextualizado do ensino de Ciências e de temas relacionados à ciência e tecnologia, tanto no ensino secundário como no ensino superior, configurando-se, desde então, o enfoque CTS na educação.

\section{O enfoque CTS na Educação e no Ensino de Ciências}

O enfoque CTS na educação, para Aikenhead (2009), surge como um slogan, em diversos países, para criar uma rede de educadores em ciências preocupados com uma nova visão para educar cientificamente, tendo em vista a necessidade de desafiar o status quo da ciência escolar. Na visão de Acevedo (1998), no entanto, esse enfoque aparece sem objetivos bem definidos. Uma das razões para isso pode estar, principalmente, nos diversos significados atribuídos à interação da ciência e da tecnologia no contexto das questões sociais ou ainda devido aos diferentes interesses e objetivos de cada país (AIKENHEAD, 1994). Todavia, essa variação de objetivos, em uma análise mais profunda "reflecte apenas a diferença de equilíbrio [grifo do autor] entre objectivos semelhantes". (AIKENHEAD, 2009, p. 23),

Pode-se, assim, dizer que o enfoque CTS na educação, ou educação CTS, "tem vindo a afirmar-se como campo de conhecimento, congregando investigadores e professores de todos os níveis de escolaridade e em todos os continentes" (MARTINS; PAIXÃO, 2011, p. 145).

Embora essa congregação, particularmente em torno de currículos em ensino de Ciências, venha se desenvolvendo no mundo inteiro, é importante considerar o

[...] contexto dos países em que as propostas curriculares de CTS foram desenvolvidas. Por se tratar de países desenvolvidos, a estrutura social, a organização política e o desenvolvimento econômico são bastante diferentes daqueles presentes no contexto brasileiro. Isso implica que seria um contra-senso a transferência acrítica de modelos curriculares desses países para o nosso meio educacional. Problemas relacionados às desigualdades sociais extremas, por exemplo, não existem nos países em que esses currículos foram desenvolvidos. Discutir modelos de currículos de CTS significa, portanto discutir concepções de cidadania, modelo de sociedade, de desenvolvimento tecnológico, sempre tendo em vista a situação sócio-econômica e os aspectos culturais do nosso país (SANTOS; MORTIMER, 2002, p. 17-18).

Por outro lado [completam os autores], a revisão da literatura internacional nos ajuda a ver que adotar propostas CTS é muito diferente de simplesmente maquiar currículos com ilustrações do cotidiano" (SANTOS; MORTIMER, 2002, p. 18). 
Desse modo, pensar efetivamente CTS na educação é refletir sobre um campo de estudo e pesquisa para melhor compreensão da ciência e da tecnologia em seu contexto social, visando oferecer formação para a construção de conhecimentos e desenvolvimento de atitudes e valores que possibilitem a participação humana de forma responsável, cidadã, democrática e fundamentada, nas decisões da ciência e da tecnologia na sociedade (ACEVEDO, 2002).

Para uma formação de professores, nessa visão, consideramos importante a observação de Aikenhead (1994) quanto ao tratamento dado aos objetivos do campo CTS. O autor discute alguns posicionamentos a respeito da estrutura de programas com enfoque CTS. Com base nas estruturas que diz ter encontrado nesses programas, organiza oito categorias CTS que vão desde a apresentação de currículo CTS com caráter motivador e eventual até aqueles que estudam a inter-relação CTS em que o conteúdo científico é mostrado de forma complementar. Das categorias apresentadas, destacamos três, por entender que se aproximam mais de nosso foco de discussão:

- Ciência por meio do conteúdo CTS - o conteúdo de ciência é focado no conteúdo CTS, que serve para organizar os conteúdos de ciência e sua sequência. Os estudantes são avaliados pela sua compreensão do conteúdo CTS, mas não na mesma proporção que o conteúdo de ciência;

- Ciência junto com o conteúdo CTS - o conteúdo CTS é o foco de ensino, sendo que o conteúdo relevante da ciência enriquece o aprendizado. Os estudantes são avaliados igualmente nos conteúdos CTS e ciência.

- Ciência incorporada ao conteúdo CTS - o conteúdo CTS é o foco de ensino, sendo o conteúdo relevante da ciência mencionada, mas não é trabalhado sistematicamente, podendo ser dada ênfase aos princípios gerais da ciência. Os estudantes são avaliados na totalidade do conteúdo CTS e parcialmente no conteúdo de ciência.

Tais categorias, especificamente no contexto escolar ou de ensino, merecem reflexão relativa ao fato de que a ciência escolar não deve estar focada unicamente em conteúdos de ciência, mas necessita manifestar as múltiplas relações/interações entre ciência, tecnologia e sociedade (MARTINS; PAIXÃO, 2009).

Isso se torna mais evidente se compreendermos que naquele contexto, o enfoque CTS

[...] tem por finalidade ajudar os estudantes a dar sentido às suas experiências cotidianas, fazendo-o de um modo que apoie a tendência natural dos estudantes para integrarem as perspectivas pessoais provenientes dos seus ambientes sociais, tecnológicos e naturais (AIKENHEAD, 2009, p. 22).

Portanto, pensar o enfoque CTS nessa perspectiva implica investir em um currículo em que "a ciência é trazida ao mundo do estudante numa base de necessidade de saber, em vez de seguir a expectativa convencional de que o estudante deve entrar no mundo da ciência para adoptar a visão de um cientista" (AIKENHEAD, 2009, p. 22). Ainda de acordo com o autor, caminhar nessa direção significa transformar o currículo científico convencional em currículo científico CTS.

De acordo com Santos e Mortimer (2002, p. 18), os princípios que diferenciam os currículos CTS dos currículos convencionais são vários:

[...] a abordagem temática, em contraposição aos extensos programas de ciências alheios ao cotidiano do aluno; o ensino que leve o aluno a participar em contraposição ao ensino passivo, imposto sem que haja 
espaço para a sua voz e suas aspirações. Enfim, uma reforma curricular de CTS implica mudanças de concepções do papel da educação e do ensino das ciências.

Amorim (1995), em revisão bibliográfica a respeito da temática, refere-se a um estudo realizado por Fensham, em 1988, para dizer que a relação CTS, no contexto curricular, visa a uma educação em ciências nos níveis mais próximos das necessidades dos estudantes. Constata que a possibilidade de interação entre ciência, tecnologia e sociedade vem vendo considerada como necessária a uma educação em ciências, haja vista seu contexto favorável ao desenvolvimento de temáticas focadas em CTS.

Diz, ainda, tomando por base os estudos de Hart e Robottom, em 1990, que o aparecimento desse enfoque se dá, no ensino de Ciências, em consequência de um repensar a educação em ciências, a partir de transformações na sociedade e na ciência e tecnologia, além do contraste entre a ciência escolar e a realidade de uma sociedade orientada pela ciência e tecnologia.

De acordo com Santos e Mortimer (2002, p. 1):

Desde a década de sessenta, currículos de ensino de ciências com ênfase em CTS - ciência, tecnologia e sociedade - vêm sendo desenvolvidos no mundo inteiro. Tais currículos apresentam como objetivo central preparar os alunos para o exercício da cidadania e caracterizam-se por uma abordagem dos conteúdos científicos no seu contexto social.

No Brasil, no entanto, embora na década de 70 já existissem materiais que continham abordagens de implicações sociais de $\mathrm{CT}$, os primeiros trabalhos no ensino de Ciências com a denominação CTS surgiram somente na década de 90 (SANTOS, 2011). Desde então, especificamente nos últimos anos dessa década, como pode ser notado na obra organizada por Santos e Auler (2011) - que traz reflexões teóricas e contribuições de investigações empíricas, mostrando a relevância desse campo de estudo e pesquisa, e consequentemente sua inserção na educação básica - estudos com enfoque CTS no ensino de Ciências vêm ganhando fôlego.

Isso torna cada vez mais evidente a necessidade de se pensar um currículo para a formação de professores de Ciências da educação básica com enfoque CTS que lhes dê condições de estabelecer relação entre Ciência-Tecnologia-Sociedade, de modo a contextualizar os conteúdos científicos, aproximando-os do contexto social dos estudantes, no sentido de contribuir para que o ensino de Ciências atinja seus objetivos, tendo por base o proposto em Brasil $(1997,2000)$. Como isso pode ser efetivado nos cursos de formação de professores de Ciências? Quais fatores favorecem, quais obstaculizam?

\section{O lugar do enfoque CTS na formação de professores de Ciências}

O que mais se encontra na literatura sobre a formação de professores, em particular no âmbito das ciências, são temas que expressam constatações de que geralmente os professores não têm tido formação adequada (SCHNETZLER, 2002) para dar conta dos desafios do processo ensino-aprendizagem, em qualquer nível de escolaridade. Quanto a uma educação CTS, os resultados têm sido semelhantes. Estudos têm evidenciado a formação insuficiente dos professores (AULER; DELIZOICOV, 2006; ACEVEDO et al., 2002; 
VIEIRA, 2003; ZEIDLER, 2005) para tratar de questões CTS no âmbito escolar ou nas instituições de ensino, de modo geral.

Isso pode ser constatado na pesquisa realizada por Zeidler et al. (2004) em que procurou identificar fatores associados a questões CTS para elaborar um modelo de trabalho em uma inter-relação de aspectos teóricos e conceituais para o desenvolvimento da educação científica. A autora reclama a ausência de sustentação teórico-epistemológica relativas àquelas questões para orientar o trabalho pedagógico do professor.

Nessa mesma direção, Vieira (2003), visando a elaborar um programa de formação de professores com enfoque CTS, realizou um estudo procurando conhecer as concepções de professores acerca desse enfoque e constatou que as concepções se aproximavam de um realismo ingênuo e pendor mais empirista, revelando uma imagem de ciência neutra, dogmática e linear, não influenciada pela sociedade. Tais concepções, de acordo com o autor aproximam-se de uma visão positivista, na qual as teorias científicas estão acima de valores e imprevistos.

Com propósito semelhante, Auler e Delizoicov (2006), no sentido de respaldar ações para o processo de formação de professores de Ciências, buscaram identificar suas compreensões sobre interações entre CTS, em termos de aproximações e distanciamentos relativamente a três parâmetros focalizados: superioridade do modelo de decisões tecnocráticas, perspectiva salvacionista da ciência-tecnologia e determinismo tecnológico. Os resultados, embora rejeitando significativamente o mito da perspectiva salvacionista da ciência-tecnologia, mostraram uma tendência ao endosso do modelo de decisões tecnocráticas, assim como um posicionamento diante do avanço científico-tecnológico, próximo do determinismo tecnológico.

Do exposto até aqui, podemos inferir que as razões que aparecem como obstaculizantes ao enfoque CTS no processo educacional estão diretamente relacionadas à formação docente ${ }^{4}$. Esta pode ser apontada como fator central para que a visão dos professores sobre interações entre ciência, tecnologia e sociedade venha sendo considerada como um dos pontos de estrangulamento da contemplação do enfoque CTS nesse processo (AULER; DELIZOICOV, 2006).

Podemos ainda inferir que tais razões estão diretamente relacionadas a dois aspectos da formação docente, o teórico-epistemológico e o ético. No primeiro, a fragilidade epistêmica, a carência de postura investigativa e prática no processo formativo, além da formação disciplinar, têm levado a uma visão de um mundo fragmentado, incapaz de dar conta da complexidade do trabalho docente; no segundo, a formação oferecida não é suficiente para desencadear no futuro professor a decisão ética de assumir o compromisso com a construção da cidadania (SEVERINO, 2004).

Se procurarmos as possíveis causas para essa formação insuficiente, vamos encontrar inúmeras considerações. Uma delas, talvez a que esteja mais em evidência na contemporaneidade, está relacionada às transformações que vêm ocorrendo na sociedade, exigindo do professor

\footnotetext{
${ }^{4}$ Todavia, concordamos com Severino (2004) que não podemos perder de vista a necessidade de condicionar os problemas da educação e suas soluções ao modo como a gestão política, econômica e administrativa tem conduzido a questão.
} 
[...] que lide com um conhecimento em construção - e não mais imutável - e que analise a educação como um compromisso político, carregado de valores éticos e morais, que considere o desenvolvimento da pessoa e a colaboração entre iguais e que seja capaz de conviver com a mudança e a incerteza (LIMA, 2004, p. 18).

Tais questões carregam em seu bojo a exigência de uma formação que proporcione aos professores condições de desenvolver saberes, com significado científico, social e cultural, para atender diferentes realidades, interesses e formas de aprender. Essa exigência, pelo fato de vivermos em uma sociedade cada vez mais orientada pela ciência e pela tecnologia (ZANCAN, 2000; ROITMAN, 2007), tem se revelado com um grau de complexidade nunca visto (NOVOA, 2001) e vem exigindo dos professores uma participação social democrática frente às novas situações.

Nesse particular, se consideramos a situação do Brasil, vamos concordar com Auler e Bazzo (2001) que a trajetória histórica do país, ainda de inexperiência democrática, pode ser considerada como um dos obstáculos para a tomada de decisões frente às novas situações, especialmente para tratar da inter-relação ciência, tecnologia e sociedade numa perspectiva mais democrática e menos tecnocrática, aspecto central do enfoque CTS.

Essa constatação torna maior o nosso desafio quanto ao processo formativo de professores, principalmente se desejamos investir em uma educação científica para todos (UNESCO, 2003), e mostra a urgência de se pensar essa formação aliada ao enfoque CTS, particularmente pelo seu caráter de repelir a tecnocracia e a concepção de tecnologia como ciência aplicada e neutra, e por enfatizar a necessidade de se valorizar a dimensão social da ciência e da tecnologia (CEREZO, 1998).

Neste aspecto, podemos constatar que os estudos realizados por Capelo e Pedrosa (2011), Vieira (2003), Auler (2002), entre outros, mostram que um processo formativo de professores de Ciências com enfoque CTS pode contribuir para melhor compreensão da ciência e da tecnologia em seu contexto social, possibilitando a construção de atitudes e valores para um agir no mundo e uma ação docente em uma visão mais responsável, cidadã e democrática.

Para além desses estudos, outras perspectivas têm sido apontadas para a efetivação do processo formativo de professores com enfoque CTS, indo desde questões amplas, em nível de políticas públicas ${ }^{5}$, até questões mais específicas voltadas para o contexto escolar.

Neste último aspecto, considerando ser a sala de aula lócus privilegiado para esse enfoque, particularmente quanto ao tratamento dado aos objetivos do campo CTS, como aponta Aikenhead (1994), retomamos a segunda categoria das três apresentadas pelo autor, Ciência junto com o conteúdo CTS, discutida no item dois deste trabalho, pois vemos que nela o conteúdo científico e CTS podem ser tratados de forma complementar. Aqui, parece-nos que a abordagem de questões sociocientíficas encontra campo fértil e desponta como possibilidade de contribuir, ao mesmo tempo, para o desenvolvimento de saberes com significado científico, social e cultural na formação de professores de Ciências e para fazer avançar o movimento educação CTS.

\footnotetext{
${ }^{5}$ Nesse caso, ver o trabalho de Dagnino, Silva e Padovanni (2011).
} 


\section{Questões sociocientíficas com enfoque CTS na formação de professores de ciências}

Questões ambientais, políticas, econômicas, éticas, sociais e culturais relativas à ciência e à tecnologia geralmente são denominadas de socioscientific issues (SSI), ou seja, questões sociocientíficas ou temas sociocientíficos (SANTOS; MORTIMER, 2009). Ainda para os autores, tais questões têm sido evidenciadas em currículos com ênfase em CTS, pois além de serem inerentes à atividade científica, visam à formação para a cidadania, por meio de estudo de assunto amplo, como poluição ambiental, por exemplo, ou de forma pontual, com situações do cotidiano que esbocem aplicações científico-tecnológicas.

Questões sociocientíficas, para alguns autores, apresentam características que as identificam. Exemplo disso pode ser encontrado em Ratcliffe e Grace (2003 apud GUIMARAES, 2011, p. 5), que apontam algumas características para essas questões, vejamos:

- Tem base na ciência, frequentemente em áreas que estão nas fronteiras do conhecimento científico.

- Envolvem a formação de opiniões e a realização de escolhas no nível pessoal e social.

- São frequentemente divulgadas pela mídia com destaque a aspectos baseados nos interesses dos meios de comunicação.

- Lidam com informação incompleta sejam elas de evidências científicas incompletas ou conflitantes e lacunas nos registros.

- Lidam com problemas locais e globais e suas estruturas sociais e políticas.

- Envolvem a análise de custo e benefício na qual os riscos interagem com valores.

- Podem envolver considerações sobre desenvolvimento sustentável.

- Envolvem valores e raciocínio ético.

- Podem requerer algum entendimento de probabilidade e risco.

- São frequentemente pontuais durante a transição de uma vida.

Tais características, a nosso ver, estão em sintonia com a categoria Ciência junto com o conteúdo CTS (AIKENHEAD, 1994), em uma perspectiva complementar, pois, centradas em questões sociocientíficas, necessitam do enfoque CTS e da ciência para sua sustentação.

De modo geral, as questões sociocientíficas com enfoque CTS, no currículo de ciências, têm tomado duas direções: uma, como temas controversos (GALVÃO; REIS; FREIRE, 2011; GUIMARÃES, 2011; ZUIN; FREITAS, 2007; REIS, 2006, entre outros), outra como conteúdos problematizados culturalmente (SIERRA et al., 2011; SANTOS; MORTIMER, 2009; MENDES; SANTOS, 2010; SANTOS, 2007, entre outros).

Os temas controversos são vistos como "problemáticas consideradas relevantes por um número considerável de pessoas - dentro do currículo de ciências" (DRIVER et al., 2000 apud ZUIN FREITAS, 2007, p. 2), pois são

[...] pouco delimitados, multidisciplinares, heurísticos, carregados de valores (invocando, por exemplo, valores estéticos, ecológicos, morais, educacionais, culturais e religiosos) e afectados pela insuficiência de conhecimento. Geralmente, o envolvimento neste tipo de problemas conduz a diversas 'soluções' alternativas, cada uma das quais com aspectos positivos e negativos. A partir destas diferentes propostas, tomase uma decisão informada que envolve a consideração e o desafio de 
opiniões, dada a impossibilidade de recurso a qualquer algoritmo para a avaliação das potencialidades e limitações. (REIS, 2006, p. 66-67).

Considerando esses aspectos, Galvão, Reis e Freire (2011), em diálogo com outros pesquisadores, dizem que o estudo de temas controversos promove a compreensão do papel da ciência e da tecnologia na sociedade, bem como o desenvolvimento cognitivo, social, político, moral e ético dos estudantes. Dizem, ainda, que esses temas, por tratarem de problemas atuais, incentivam a participação dos estudantes e facilitam o domínio de conhecimentos favoráveis à resolução desses problemas. Além disso, destacam que a abordagem de questões sociocientíficas de temas controversos no ensino de Ciências tem sido amplamente indicada para desenvolver nos estudantes a capacidade de argumentação.

Nessa mesma direção, Guimarães (2011), ao verificar em que extensão professores de Ciências em formação eram capazes de criar argumentos a partir da abordagem de temas sociocientíficos controversos, conclui que essa abordagem, além de ser importante para o desenvolvimento da argumentação, é favorável à criação de um contexto para o aprendizado de conteúdo científico.

Também Galvão, Reis e Freire (2011), visando a compreender como professores avaliam as potencialidades da abordagem dos temas em questão em seu processo formativo, constatam que essa abordagem é reconhecida pelos professores como relevante pelo confronto de argumentos contrastantes, pela oportunidade de construção e aprofundamento de conhecimentos e por constituir um contexto e um pretexto para novos estudos e atividades educativas com foco CTS.

Na outra direção, como conteúdos problematizados culturalmente, Santos e Mortimer (2009, p. 192) mostram que o estudo de questões sociocientíficas em currículos CTS pode ocorrer

[...] de maneira que os aspectos ambientais, políticos, econômicos, éticos, sociais e culturais relativos à ciência e à tecnologia venham a emergir de conteúdos problematizados culturalmente [...]. Isso significa que, nesse caso, eles não são explorados necessariamente como perguntas controversas ou como temas do currículo, mas sim como processo constante de reflexão sobre o papel social da ciência.

Nesse caso, a abordagem de questões sociocientíficas com enfoque CTS, assume uma visão crítica ${ }^{6}$, que pode ser compreendida como uma atitude de assegurar um comprometimento social dos professores em formação, sem perder de vista o contexto da sociedade tecnológica atual.

Com isso, a abordagem de questões sociocientíficas em sala de aula, a partir de uma visão crítica, tende a provocar o surgimento de

[...] diferentes pontos de vista, que poderão ser problematizados mediante argumentos coletivamente construídos, com encaminhamentos de possíveis respostas a problemas sociais relativos à ciência e à tecnologia. Esse diálogo cria condições para a difusão de valores assumidos como

\footnotetext{
${ }^{6}$ Essa visão tem sido sustentada teoricamente, no Brasil, principalmente no pensamento freireano, sendo consideradas obras centrais para essa sustentação, Freire 1967 e 1972.
} 
fundamentais ao interesse social, aos direitos e aos deveres dos cidadãos, de respeito ao bem comum e à ordem democrática (SANTOS, 2007, p. 6).

Com essa visão, Santos e Mortimer (2009), ao pesquisarem sobre a introdução de questões sociocientíficas nas aulas de Ciências com o propósito de identificar suas potencialidades, limitações e implicações para o currículo e para o processo de formação de professores, apontam evidências de que essa abordagem pode potencializar as interações dialógicas, facilitando situações vivenciais dos estudantes e a introdução de atitudes e valores em uma visão humanística.

Podemos dizer, assim, que um currículo que valorize a abordagem de questões sociocientíficas com enfoque CTS no sentido de potencializar habilidades críticas na formação cidadã (SIERRA et al., 2011), deve tratar tais questões de forma contextualizada. Para tanto, vemos a importância de se considerar o que Pedretti (2003 apud GALVÃO, REIS, FREIRE, 2011, p. 506) postula como princípios orientadores à educação CTS:

1. A contribuição para o desenvolvimento sustentável do planeta através do estudo da utilização sistemática de recursos e da consideração das necessidades humanas a longo prazo;

2. A compreensão dos processos de tomada de decisão a nível governamental e empresarial;

3. A promoção do raciocínio moral e ético acerca da ciência;

4. A compreensão e a discussão da dimensão política da ciência;

5. O exercício de capacidades intelectuais e éticas na determinação dos aspectos positivos e negativos do desenvolvimento científico e tecnológico e no reconhecimento das forças políticas e sociais que governam o desenvolvimento e a distribuição dos conhecimentos e artefatos científicos e tecnológicos;

6. A capacitação dos cidadãos para uma acção responsável na transformação da sociedade; e

7. A compreensão da natureza da ciência e das suas interacções com a tecnologia e a sociedade.

Embora reconhecendo a relevância desses princípios, em seu conjunto, queremos destacar a necessidade de atenção cuidadosa aos itens 3 e 7, por entender que, sem eles, pouco podemos avançar na formação de professores de Ciências em uma visão crítica, pois currículos com essa visão precisam considerar "o contexto da sociedade tecnológica atual, caracterizado de forma geral por um processo de dominação dos sistemas tecnológicos que impõem valores culturais e oferecem riscos para a vida humana" (SANTOS, 2007, p. 8).

É por esse motivo que estamos compreendendo que questões sociocientíficas com enfoque CTS, sejam como temas controversos, sejam como conteúdos problematizados culturalmente, podem contribuir para a formação de professores e para os objetivos da educação CTS, desde que atenção a tais questões estejam centradas em um processo de intensa reflexão sobre o papel da ciência e da tecnologia na sociedade.

Com isso, estamos assumindo, com base no entendimento de Ciência junto com conteúdo CTS (AIKENHEAD, 1994), que esses dois temas podem ser vistos no sentido de complementaridade, sendo esta condicionada ao tratamento dado aos objetivos do campo CTS, como sugere o autor. Nesse caso, esses objetivos devem contemplar aspectos teóricoepistemológicos e éticos, apontados como necessários a uma formação de professores que torne possível a efetivação do enfoque CTS no processo educacional, particularmente no ensino de Ciências. 
Vista desse modo, a abordagem de questões sociocientíficas com enfoque CTS pode favorecer o desenvolvimento de saberes com significado científico, social e cultural na formação de professores de Ciências. Isso porque permite "uma compreensão de que formar cidadãos não se limita a nomear cientificamente fenômenos e materiais do cotidiano ou explicar princípios científicos e tecnológicos do funcionamento de artefatos do dia-a-dia" (SANTOS, 2007, p. 5), mas acima de tudo romper com os mitos da visão reducionista de CTS (AULER; DELIZOICOV, 2006), rumo a um posicionamento mais crítico, que resulte no comprometimento dos professores perante si e a sociedade, o que possivelmente contribuirá para avanços no ensino de Ciências e na educação CTS.

\section{Considerações finais}

No texto, vimos que o enfoque CTS, embora tenha se tornado uma temática central de discussão na educação, particularmente no campo de pesquisa, não conseguiu alterar os currículos formativos das instituições de ensino, que permanecem sem alterações significativas em seu modelo e, consequentemente, não foi incorporado efetivamente ao processo educacional. Os caminhos percorridos para ajudar a conhecer as razões para isso e, ao mesmo tempo, encontrar alternativa que pudesse contribuir para uma inserção efetiva do enfoque CTS no processo educacional permitiram-nos chegar a três evidências principais.

A primeira evidência mostra que o movimento CTS como campo multidisciplinar, ao enfatizar a dimensão social da ciência e da tecnologia, rejeita a imagem da ciência como uma atividade neutra, pura e aplicada, repelindo assim a tecnocracia. Isso refletiu na educação, levando ao aparecimento de propostas para um planejamento mais crítico e contextualizado do ensino de ciências e de temas relacionados à ciência e à tecnologia nos diversos níveis de ensino. Com isso, o enfoque CTS surge na educação como possibilidade de contextualização dos conteúdos científicos, aproximando-os do contexto social dos estudantes, de modo a contribuir para que o ensino de Ciências atinja seus objetivos nos diversos níveis de ensino.

No entanto, a segunda evidência revela que o enfoque CTS não tem sido efetivamente apropriado pelas instituições de ensino. A causa apontada para isso, não obstante o reconhecimento das condições socioeconômicas do Brasil, muito diversas daquele em que o enfoque CTS se desenvolveu, centra-se na formação de professores. O estudo mostrou que os problemas dessa formação estão focados nos aspectos teórico-epistemológicos e éticos, que têm levado a uma visão sobre CTS que se aproxima de um realismo ingênuo e de pendor empirista, fortemente ligado a uma visão positivista diante do avanço científicotecnológico. Disso decorre uma visão de mundo fragmentada, insuficiente para desencadear no futuro professor a decisão ética de assumir o compromisso com a construção da cidadania.

Tais questões trazem à baila a terceira evidência, que diz respeito à urgência de se pensar o processo formativo de professores de Ciências aliado ao enfoque CTS. Na busca de alternativa para a questão, visualizamos a categoria Ciência junto com o conteúdo CTS (AIKENHEAD, 1994), pois nela o conteúdo científico e CTS podem ser tratados de forma complementar. Essa possibilidade se mostrou fértil para a abordagem de questões sociocientíficas, seja como temas controversos, seja como conteúdos problematizados culturalmente, desde que tais questões tenham como foco um processo reflexivo sustentado por uma visão crítica sobre o papel da ciência e da tecnologia na sociedade. 
Por fim, apostamos que a abordagem de questões sociocientíficas, no sentido de complementaridade, condicionada ao tratamento dado aos objetivos do campo da educação CTS e que contemple aspectos teórico-epistemológicos e éticos do enfoque CTS, pode desenvolver saberes com significado científico, social e cultural na formação de professores de Ciências. Essa contribuição ao processo formativo de professores poderá implicar melhorias no ensino de Ciências e avanços na educação CTS.

Merece ainda ressaltar que as discussões estabelecidas refletem um esforço de colaboração para (re)pensar os currículos com enfoque CTS no processo formativo de professores da educação básica, particularmente de Ciências, que resultem na formação de um professor que, consciente e autonomamente, reconheça e assuma seu compromisso com a construção da cidadania na qualidade de profissional da educação, tendo condições para um enfrentamento crítico perante os desafios de lidar com a questão ciênciatecnologia-sociedade.

\section{Referências}

ACEVEDO, J. A. Cambiando la práctica docente en la enseñanza de las ciencias a través de CTS. Organización de estados iberoamericanos (OEI)/sala de lectura CTS+I. 2001. Disponível em: <http://www.oei.es/salactsi/acevedo2.htm>. Acesso em: 13 mar. 2012.

ACEVEDO, J. A. et al. Persistência de las actitudes y creencias CTS en la profesión docente. Revista electrónica de enseñanza de las Ciencias, v. 1, n. 1, p. 1-27, 2002. Disponível em: <http://www.saum.uvigo.es/reec>. Acesso em: 13 mar. 2012.

AIKENHEAD, G. S. Educação científica para todos. Portugal: Edições Pedago, 2009.

What is STS teaching? In: SOLOMON, J,; AIKENHEAD, G.S. (Eds.). STS education: international perspectives on reform. New York: Teachers College Press, 1994, p. 47-59. Disponível em: <http://www.usask.ca/education/people/aikenhead/sts05.htm>. Acesso em: 13 mar. 2012.

AMORIM, A. C. R. O Ensino de Biologia e as relações entre ciência/tecnologia/ sociedade: o que dizem os professores e o currículo do Ensino Médio? Dissertação de mestrado em Educação UNICAMP, Campinas, 1995.

AULER, D. Interações entre ciência-tecnologia-sociedade no contexto da formação de professores de Ciências. Tese de doutorado em Educação - Universidade Federal de Santa Catarina, Florianópolis, 2002.

AULER, D.; BAZZO, W. A. Reflexões para a implementação do movimento CTS no contexto educacional brasileiro. Ciência \& Educação, v.7, n.1, p. 1-13, 2001.

AULER, D.; DELIZOICOV, D. Ciência-Tecnologia-Sociedade: relações estabelecidas por professores de ciências. Revista electrónica de enseñanza de las Ciencias, v. 5, n. 2, p. 337-355, 2006.

BRASIL. Ministério da Educação. Secretaria de Educação Média e Tecnológica. Parâmetros curriculares nacionais - Ensino Médio: Ciências da Natureza, Matemática e suas Tecnologias. Brasília: SEMT, 2000.

BRASIL. Secretaria da Educação Fundamental. Parâmetros curriculares nacionais: ciências naturais. Brasilia: MEC/SEF, 1997.

CACHAPUZ, A. et al. Do estado da arte da pesquisa em educação em Ciências: linhas de pesquisa e o caso "Ciência-Tecnologia-Sociedade". Alexandria: revista de educação em ciência e tecnologia, v.1, n.1, p. 27-49, mar.2008. 
CAPELO, A.; PEDROSA, M. A. Formação inicial de professores de ciências, problemas atuais e percursos investigativos. In: SANTOS, W. P. dos; AULER, D. CTS e educação científica: desafios, tendências e resultados de pesquisa (Orgs.). Brasília: Editora Universidade de Brasília, 2011, p. 439461.

CEREZO, J. A. L. Ciência, Tecnología y Sociedad: el estado de la cuestión en Europa y Estados Unidos. Revista iberoamericana de educación, n. 18, p. 13-40, Septiembre/diciembre, 1998.

DAGNINO, R.; SILVA, R. B. da; PADOVANNI, N. Por que a educação em ciência, tecnologia e sociedade vem andando devagar? In: SANTOS, W. P. dos; AULER, D. CTS e educação científica: desafios, tendências e resultados de pesquisa (Orgs.). Brasília: Editora Universidade de Brasília, 2011, p. 99-134.

FREIRE, P. Educação como prática da liberdade. Rio de Janeiro: Paz e Terra, 1967.

FREIRE, P. Pedagogia do oprimido. Rio de Janeiro: Paz e Terra, 1972.

GALVÃO, C.; REIS, P.; FREIRE, S. A discussão de controvérsias sociocientíficas na formação de professores. Ciência \& Educação, v. 17, n. 3, p. 505-522, 2011.

GUIMARÃES, M. A. Raciocínio informal e a discussão de questões sociocientíficas. o exemplo das células-tronco humanas. Tese de doutorado em Educação para a Ciência - Universidade Estadual Paulista, Faculdade de Ciências, Bauru, 2011.

INVERNIZZI, N.; FRAGA, L. (Orgs.). Estado da arte na educação em Ciência, Tecnologia, Sociedade e Ambiente no Brasil. Ciência \& Ensino, v.1, n. especial, s/p, nov. 2007. Apresentação.

LIMA, E. F. Formação de professores - passado, presente e futuro: o curso de Pedagogia. In: MACIEL, L. S. B.; SHIGUNOV NETO, A. S. Formação de professores: passado, presente e futuro. São Paulo: Cortez, 2004, p. 15-34.

LINSINGEN, I. Perspectivas educacionais CTS: aspectos de um campo em consolidação na América latina. Ciência \& Ensino, v. 1, n. especial, p. 1-19, nov. 2007.

MARTINS, I. P.; PAIXÃO, M. de F. Perspectivas atuais ciência-tecnologia-sociedade no ensino e na investigação em educação em ciência. In: SANTOS, W. P. dos; AULER, D. CTS e educação científica: desafios, tendências e resultados de pesquisa (Orgs.). Brasília: Editora Universidade de Brasília, 2011, p. $135-160$.

MENDES, M. R. M.; SANTOS, W. L. P. dos. Discussões de temas sociocientíficos e interações discursivas em aulas de Química: o papel da verbalização e da articulação conceitual. In: ENCONTRO NACIONAL DE ENSINO DE QUÍMICA, 15, 2010, Brasília, DF. Anais... Brasília: Universidade de Brasília, 2010, p. 1-12. Disponível em: <http://www.xveneq2010.unb.br/resumos/R1261-1.pdf>. Acesso em: 13 mar. 2012.

NÓVOA, A. O professor pesquisador e reflexivo. 2001. Entrevista. Disponível em: <http://tvbrasil.org.br/saltoparaofuturo/>. Acesso em: 13 mar. 2012.

REIS, P. Uma iniciativa de desenvolvimento profissional para a discussão de controvérsias sociocientíficas em sala de aula. Interacções, n.4, p. 64-107, 2006.

ROITMAN, I. Educação científica: quanto mais cedo, melhor. Brasilia, DF: RITLA, 2007.

SANTOS, W. L. P. dos. Significados da educação científica com enfoque CTS. In: SANTOS, W. P. dos; AULER, D. CTS e educação científica: desafios, tendências e resultados de pesquisa (Orgs.). Brasília: Editora Universidade de Brasília, 2011, p. 21-48.

SANTOS, W. L. P. Contextualização no ensino de ciências por meio de temas CTS em uma perspectiva crítica. Ciência \& Ensino, v. 1, n. especial, p. 1-12, nov. 2007. 
SANTOS, W. P. dos; AULER, D. Apresentação. In: SANTOS, W. P. dos; AULER, D. CTS e educação científica: desafios, tendências e resultados de pesquisa (Orgs.). Brasília: Editora Universidade de Brasília, 2011a, p. 11-20.

SANTOS, W. P. dos; AULER, D. CTS e educação científica: desafios, tendências e resultados de pesquisa (Orgs.). Brasília: Editora Universidade de Brasília, 2011b.

SANTOS, W. L. P. dos; MORTIMER, E. F. Abordagem de aspectos sociocientíficos em aulas de ciências: possibilidades e limitações. Investigações em ensino de Ciências, v. 14, n. 2, p. 191-218, 2009.

SANTOS, W. L. P. dos; MORTIMER, E. F. Uma análise de pressupostos teóricos da abordagem CTS (Ciência-Tecnologia-Sociedade) no contexto da educação brasileira. Ensaio: pesquisa em educação em Ciências, Belo Horizonte, v.2, n.2, p. 1-23, dez. 2002.

SCHNETZLER, R. P. (2002). Prática de ensino nas ciências naturais: desafios atuais e contribuições de pesquisa. In: ROSA, D. E. G.; SOUZA, V. C. (Orgs.). Didática e práticas de ensino: interfaces com diferentes saberes e lugares formativos. Rio de Janeiro: DP\&A, p. 205-222.

SEVERINO, A. J. A formação e a prática do professor em face da crise atual dos paradigmas educacionais. Ciência \& Opinião, Curitiba, v. 1, n. 2/4, p. 15-31, jul. 2003/dez. 2004.

UNESCO. A ciência para o século XXI: uma nova visão e uma base de ação. 3 ed. Brasília: ABIPTI, 2003.

VACCAREZZA. L. S. Ciencia, Tecnología y Sociedad: el estado de la cuestión en América Latina. Revista iberoamericana de educación, n.18, p. 41-68, septiembre/diciembre, 1998.

VIEIRA, R. M. Formação continuada de professores do $1 .^{\circ}$ e $2 .^{\circ}$ ciclos do ensino básico para uma educação em Ciências com orientação CTS/PC. Tese de Doutorado em Didática - Universidade de Aveiro, Portugal. 2003.

ZANCAN, G. T. Educação científica: uma prioridade nacional. São Paulo em Perspectiva, São Paulo, v.14, n.1, p. 3-7, 2000.

ZEIDLER, D. L. et al. Beyond STS: a research-based framework for socioscientific issues education. Published online, 2005, p. 357-377. Disponível em: <http://faculty.education.ufl.edu/tsadler/BeyondSTS.pdf>. Acesso em: 13 mar. 2012.

ZUIN, V. G; FREITAS, D. de. A utilização de temas controversos: estudo de caso na formação de licenciandos numa abordagem CTSA. 2. Ciência \& Ensino, vol. 1, n. 2, p. 1-9, jun. 2007. 